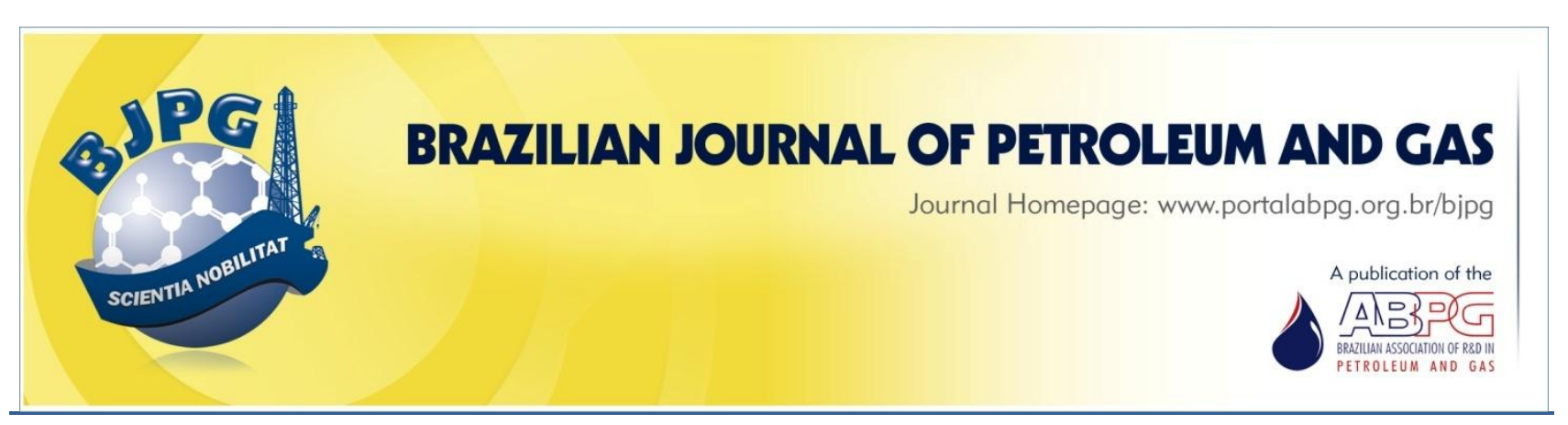

\title{
COALESCER BED MODELING TO MIXTURE OIL/WATER: TREATMENT USING ANSYS CFX
}

\author{
${ }^{a}$ Ferreira, D. N. ${ }^{1}{ }^{\text {a }}$ Marinho, J. L. G.; ${ }^{\text {a }}$ Oliveira, L. M. T. M. \\ a Universidade Federal de Alagoas (UFAL), Unidade Acadêmica Centro de Tecnologia, Maceió - AL - Brasil \\ Received: 08.01.2018 / Revised: 11.05.2018 / Accepted: 02.08.2018 / Published on line: 17.10.2018
}

\begin{abstract}
Produced water is one of the greatest concerns in oil industry due to the quantities of this effluent produced and the negative environmental impacts that it can cause. Based on these considerations and on the difficulty in removing emulsified oil in water, the study of methods to treat this effluent becomes of great relevance. The use of computational fluid dynamics is an alternative to solve this problem for the economical and time advantages it presents, and the possibility of achieving reliable results. This paper studies the use of a coalescer bed to treat oil/water mixture behavior. Results of droplets distribution, size, oil flow, and fluid dynamics equipment behaviour are analyzed and discussed.
\end{abstract}

\section{KEYWORDS}

produced water; coalescer bed; Computational Fluid Dynamics (CFD); coalescence; separation

\footnotetext{
${ }^{1}$ To whom all correspondence should be addressed.

Address: Universidade Federal de Alagoas (UFAL), Unidade Acadêmica Centro de Tecnologia, Av. Lourival Melo Mota, s/n Tabuleiro, Maceió - AL - Brasil.

ZIP Code: 57072-970| Telephone: +55 82 3214-1271| e-mail: davi.nf@hotmail.com doi:10.5419/bjpg2018-0013
} 


\section{INTRODUCTION}

Produced water is the main effluent generated by oil exploration and it is one of the biggest concerns in oil industry due to the quantities it produces and the fact that it generates several kinds of waste that can lead to environmental problems (Martins, 2015). According to Silva (2000), produced water usually contains high salinity, suspended oil particle, chemicals added during the production process, heavy metals, and it may contain radioactivity, making it a pollutant difficult to dispose in the environment.

Among these components, the oil is highlighted due to its low biodegradability, its tendency to accumulate in the surface, and for the fact that it may cause a limitation in the rate of oxygen transfer between air and liquid, causing negative impacts on water receptors (Metcalf, 1991, apud Lopes 1999). Therefore, it becomes critical to separate the oil present in produced water. Such process can be done using various methods and equipments, such as adsorption, hydrocyclones, flotation, demulsification, and filtration (Ahmadun et al., 2009).

Oil can be present in produced water in its free form, emulsified, and dissolved. This latter form is a cause of greater concern due to the difficulty of its removal (Motta et al., 2013). An emulsion is formed when one liquid disperses in another in the form of droplets, and they are immiscible with each other (Schramm, 1992, apud Lida et al. 2007). Differently from that present in the free form, when the droplets are larger than $100 \mu \mathrm{m}$ and are removable with the use of gravitational separators, the emulsified oil, due to its smaller diameter, can constitute a very small and dispersed fraction, making its coalescence and separation a difficult process (Motta et al., 2015; Speth et al., 2002).

According to Maiti et al. (2011), researchers have focused their attention on coalescing methods for separation of emulsified oil in oil/water mixtures. Coalescer beds operate to induce coalescence with the emulsion flow though a porous bed, causing droplet size increase (Motta, 2014; Motta et al., 2015; Maiti et al., 2011; Li \& Gu, 2004; Speth et al., 2002). Govedarica et al. (2013) noted that this method has as main advantages the continous operation during a long period, the possibility of automation, mobility, high separation efficiency, and simplicity.

The most common types of coalescer beds used are the fiber bed and the granular bed (Motta et al., 2015; Sherony et al., 1971, apud Li \& Gu, 2004; Bradley, 1985, apud Li \& Gu, 2004). They differ from each other mainly in their physical characteristics, although both have porous properties. Spielman and Su (1977) suggested that fibrous beds could be made in a way that would allow greater porosity and surface area than granular beds.

Inside this context, Sokolovic and Sokolovic (2004) worked with fibrous beds with high porosity, between 0.97 and 0.85 . Li and Gu (2004) analyzed the coalescence of and oil-in-water emulsion using granular beds with porosities equal to 0.341 and 0.384. Spielman and Su (1977) used a granular bed with porosity equal to 0.38 for coalescence of oil droplets with diameters between 1 and $5 \mu \mathrm{m}$.

In view of the necessity to remove the oil from the produced water and due to the economic importance of the petroleum activity, studies related to techniques that promote this separation are highly relevant, as well as the ones addressing the use of other methods that can remove emulsified oil. Among such available study methods, Computational Fluid Dynamics (CFD) has had notoriety and has been widely used to analyze problems involving produced water treatment. The main advantage of CFD is the reduction in the number of experiments and the possibility of numerical analysis of several important parameters in the problem studied (Coelho, 2011), such as pressure, saturation, and velocity fields.

Braga et al. (2015) used Ansys ${ }^{\circledR}$ CFX to develop a hydrocyclone for treatment of flows with mass fraction of oil equal to $1 \%$. Huang (2005) used the Ansys ${ }^{\circ}$ Fluent to simulate a hydrocyclone for oilwater separation using and Eulerian-Eulerian approach and Reynolds-stress model. Cai et al. (2016) applied computational fluid dynamics for analyze a compact flotation unit (CFU) to oil-water separation, observing that the correct increase of inlet flow, decrease of annular breadth, and increase of height in the preliminary separation zone can promote the collision and coalescence process for oil droplets effectively.

Therefore, the study of a coalescer bed 
behavior performed in CFD environment can increase the comprehension and validation of phenomena involving the interaction between fluid and porous medium.

This work has the objective of analyzing the coalescence and separation of an oil-in-water mixture in a coalescer column using the CFD software Ansys CFX 13.0. After modelling and simulation, one could observe the saturation level of dispersed phase to indicate the degree of coalescence and the superficial velocity field with the goal of finding the better operational range for this property. All the parameters analyzed were compared with other results found in literature. In addition, this study tried to establish a process trend with the objective of padronizing the coalescer column operation.

\section{METHODOLOGY}

\subsection{Geometry and Mesh}

For the proposed analysis, a geometry was gererated using the software Ansys ${ }^{\circ}$ ICEM CFD, based on the equipment used by Dacal (2017),
Table 1. Characteristics of the coalescer bed geometry.

\begin{tabular}{lc}
\hline Inlet diameter & $\mathrm{d}=0.0127 \mathrm{~m}$ \\
Outlet diameter & $\mathrm{d}=0.0127 \mathrm{~m}$ \\
Equipment diameter & $\mathrm{D}=0.1 \mathrm{~m}$ \\
Column length & $\mathrm{L}=0.85 \mathrm{~m}$ \\
Porous bed length & $\mathrm{I}=0.05 \mathrm{~m}$ \\
Inclination & $\alpha=5^{\circ}$ \\
\hline
\end{tabular}

corresponding to a porous bed with a length equal to $5 \mathrm{~cm}$ and an inclined column with total length of $85 \mathrm{~cm}$. In Figure 1 it is possible to observe the geometry corresponding to the analyzed porous bed.

The geometry corresponding to the proposed coalescer bed has the following general characteristics according to Table 1.

Based on the geometry elaborated, a tetrahedral unstructured mesh was generated to represent the control volume to be analyzed. Ferreira et al. (2017) analyzed the pressure drop in curved pipes and concluded that tetrahedral

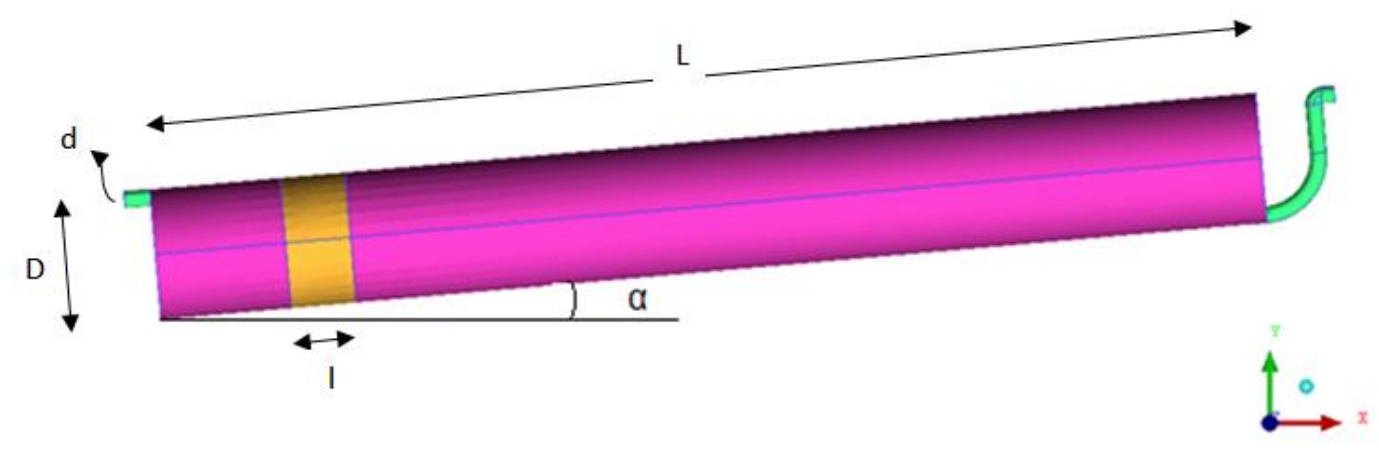

Figure 1. Geometry corresponding to an equipment with a porous bed (I) with lenght equal to $5 \mathrm{~cm}$.

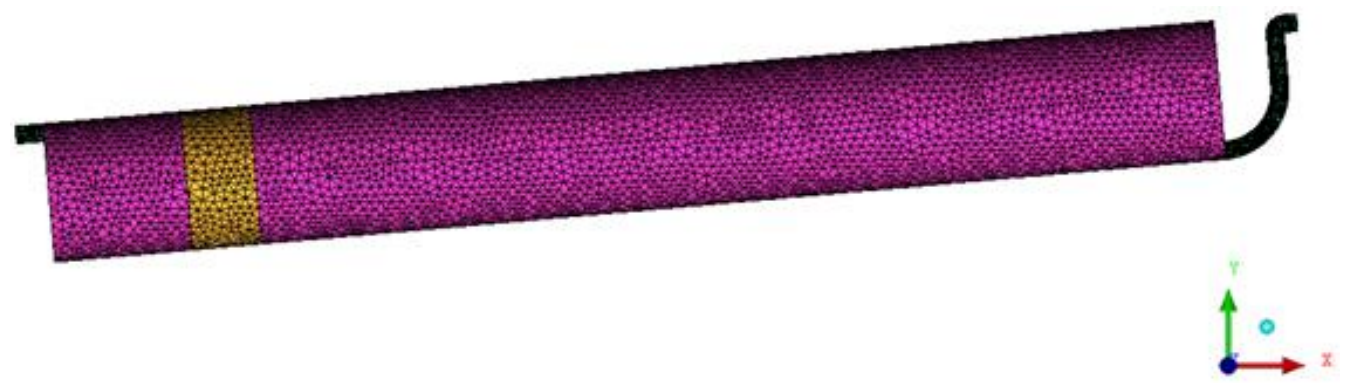

Figure 2. Unstructured mesh generated. 
Table 2. Mesh generated characteristics.

\begin{tabular}{cc}
\hline Elements & 151,521 \\
Nodes & 27,029 \\
\hline
\end{tabular}

unstructured meshes are well suited for curve geometries. The mesh generated and its characteristics can be observed, respectively, in Figure 2 and in Table 2.

\subsection{Mathematical Modeling}

To solve the proposed problem, the study used a model based on the principles of mass and momentum conservation, assuming the following considerations:

- Isothermal and incompressible flow;

- Transient state;

- Gravitational effects;

- Three-dimensional domain;

- Constant fluid properties;

- There inexistence of chemical reactions.

This modeling used the Eulerian-Eulerian formulation, in which the oil was considered the dispersed phase in the particle model. This formulation, also known as a multifluid approach, consists of an extension of single-phase mathematical modeling to multiphasic flow. It is characteristic of this type of formulation that the interactions between phases are expressed in a continuous form, being necessary the correct determination of the control volume so that it has representative properties such temperature and velocity (Marinho, 2012).

\subsubsection{Equations for the fluid domain}

To represent the phonomena that occurred in the fluid domains, the equations of mass $e$ momentum conservation were applied, see Equations 1 and 2 (Munson, 2002).

$\frac{\partial}{\partial t} \int \rho d V+\int \rho v \cdot \hat{n} d A=0$

$\frac{\partial}{\partial t} \int V \rho d V+\int v \rho V \cdot \widehat{n} d A=\sum F$
In Equation 1, the first term refers to the mass variation in control volume over time, while the second is the mass flow in the control surface (Munson, 2002). In Equation 2, the first term refers to the rate of change of the linear momentum in the control volume over time, and the second term represents the liquid flow of linear momentum in control surface (Munson, 2002). Finally, $\sum F$ represents the field and superficial forces acting on the control volume (Munson, 2002). In the above equations, $\rho$ is the specific mass, $\mathrm{V}$ is the volume, $\hat{n}$ is the normal vector to the control surface, and $A$ is the control surface area.

\subsubsection{Equations for porous domain}

To represent the phenomena to be observed in porous domain, the study used the equations of mass and momentum conservation, represented, respectively, by Equations 3 and 4 (Ahmed, 2000).

$$
\begin{array}{r}
\frac{\partial}{\partial t}(\gamma \rho)+\left[\frac{\partial}{\partial x}\left(U_{x} \rho\right)+\frac{\partial}{\partial y}\left(U_{y} \rho\right)\right. \\
\left.+\frac{\partial}{\partial z}\left(U_{z} \rho\right)\right]=0
\end{array}
$$

$\vec{U}=\frac{-K}{\mu}(\nabla p-\rho g \nabla D)$

In the equations above, $\rho$ is the specific massa, $\gamma$ is the absolute porosity of the porous domain, $U_{x}, U_{y}, U_{z}$ are the components of the velocity vector, $K$ is the absolute permeability, $\mu$ is the viscosity of the fluid, $g$ is the acceleration of gravity, $\nabla p$ is the pressure gradient, and $\nabla D$ is the height variation. Equations 3 and 4, respectively, represent the mass conservation in porous media; and the Darcy's Law that is relative to momentum conservation in a porous volume.

\subsubsection{Drag model}

To obtain results closer to the reality in the proposed model, the study used the drag model developed by Ishii and Zuber (1979). The model analyzes the relative movement between two phases for dispersed flows, comparing the experimental data obtained from a series of particles concentration intervals and the Reynolds number. From the results obtained in their experiments, the researchers developed a model able to represent the characteristics of fluid 
particle systems for higher Reynolds numbers or higher concentration regimes.

\subsubsection{Coalescence model}

To represent the coalescence phenomenon, this study chose the proposed model by Prince and Blanch (1990). This model represents bubbles coalescence considering the collision between them due to the turbulence, flutuability, laminar shear, and coalescence efficiency of the collisions, as well the separation as a function of the interaction with turbulent swirls.

Prince and Blanch model assumes that the coalescence of two bubbles occurs in three steps. First, there is a clash between them, with the entrapment of a small mass of fluid. Then, the entrapped fluid is drained until the film that separates the bubbles reaches a critical thickness. Following, there is a rupture, and the particles come together (Ansys, 2011). The coalescence time can be represented by Equation 5 .

$t_{i j}=\left\{\frac{r_{i j}^{3} \rho_{i}}{16 \sigma}\right\}^{1 / 2} \ln \frac{h_{o}}{h_{f}}$

Where $h_{o}$ is the initial film thickness of the bubble, $h_{f}$ is the critical film thickness, when the rupture occurs, $\rho$ is the specif mass of the fluid, $\sigma$ is the interfacial tension and $t$ is the coalescing time. The time in which the bubbles remain in contact depends on their size and the intensity of the turbulence. High levels of turbulence increase the probability that the swirls separate the particles, while the increase in size expands the contact area between them. According Levich (1963), the contact time between two bubbles can be represented by Equation 6 .

$\tau_{i j}=\frac{r_{b}^{\frac{2}{3}}}{\epsilon^{\frac{1}{3}}}$

Where $r_{b}$ is the particle radius, $\epsilon$ is the energy dissipation rate per mass, and $\tau$ is the contact time.

According to Chester and Hoffman (1982), Equation 7 represents the coalescence equivalent radius for bubbles with different diameters.
Table 3. Physical properties of fluids.

\begin{tabular}{ccc}
\hline Fluid & $\begin{array}{c}\text { Density } \\
\left(\mathbf{k g} / \mathbf{m}^{3}\right)\end{array}$ & $\begin{array}{c}\text { Dynamic } \\
\text { Viscosity (Pa.s) }\end{array}$ \\
\hline Oil $^{(a)}$ & 823.4 & $8.62 \times 10^{-3}$ \\
Water $^{(b)}$ & 997 & $8.899 \times 10^{-4}$ \\
\hline
\end{tabular}

Source: (a) Dacal (2017); (b) Ansys (2011).

Table 4. Physical properties of the coalescer bed.

\begin{tabular}{cc}
\hline Porosity $^{\text {(a) }}$ & $\phi=0.94$ \\
Permeability & $K=2000 \mathrm{D}$ \\
\hline
\end{tabular}

Source: (a) Dacal (2017).

Table 5. Initial conditions.

\begin{tabular}{cc}
\hline Pressure $^{(\mathrm{a})}$ & $101,325 \mathrm{~Pa}$ \\
Oil content $^{(\mathrm{a})}$ & $400 \mathrm{mg} / \mathrm{L}$ \\
Simulation time $^{\text {(a) }}$ & $45 \mathrm{~min}$ \\
Fluids velocity & $\mathrm{V}=0 \mathrm{~m} / \mathrm{s}$ \\
\hline
\end{tabular}

Source: ${ }^{(a)}$ Dacal (2017).

Table 6. Boundary conditions.

\begin{tabular}{cc}
\hline Inlet & Flow rate -85 ou 110 \\
& $\mathrm{~L} / \mathrm{h}$ \\
Outlet & $\mathrm{P}-101,325 \mathrm{~Pa}$ \\
Oil content (inlet) & $400 \mathrm{mg} / \mathrm{L}$ \\
Emulsion diameter & $50-100 \mu \mathrm{m}$
\end{tabular}

Source: Adapted from Dacal (2017).

$r_{i j}=\frac{1}{2}\left(\frac{1}{r_{b i}}+\frac{1}{r_{b j}}\right)^{-1}$

Where $r_{i j}$ is the radius of a particle resulting from the union of two other particles with diameters equal to $r_{b i}$ and $r_{b j}$.

\subsection{Boundary conditions and physical properties of fluids}

Tables 3, 4, 5 and 6 , respectively, list the physical properties of fluids, the properties of coalescer bed, and the initial and boundary conditions of the control volume analyzed.

In the analyzed problem, the oi is the dispersed phase and the water the continuous one. An oil/water surface tension of $0.027 \mathrm{~N} \cdot \mathrm{m}^{-1}$ was adopted. 


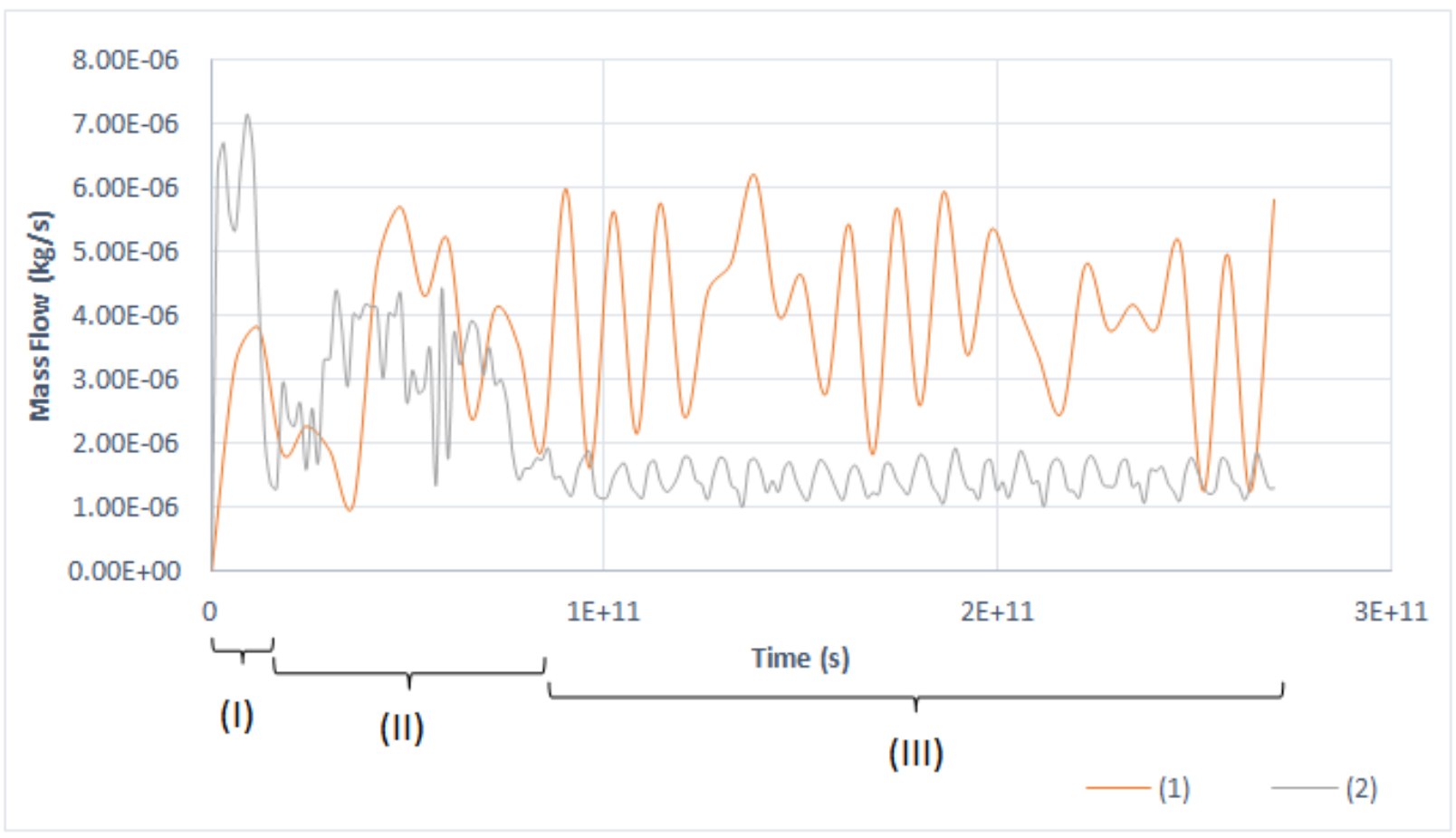

Figure 3. Mass flow of oil at the outlet for an inlet flow rate of $85 \mathrm{~L} / \mathrm{h}$.

The emulsion is a mixture composed of water and an oil phase that is represented by a polydispersed fluid with groups of particle diameters ranging from $50 \mu \mathrm{m}$ and $100 \mu \mathrm{m}$, according to the modeling adopted.

The porous domain was considered isotropic. A maximum of 10 interactions per timestep and a Mean Quadratic Residue equal to $10^{-6}$ were adopted. Each timestep represents a part of the total time after discretization.

\subsection{Case analyses}

Studies using two different timesteps were used, resulting in the analysis of two cases: (1) with timesteps of 60 seconds; and (2) with timesteps of 15 seconds. For both cases, a polydispersed fluid composed of ten different size groups: 50,60, 65, $70,75,80,85,90,95$, and $100 \mu \mathrm{m}$ represented the oil.

The groups that compose the emulsion, in both cases, have the same volume fraction on initialization and on inlet flow.

Studies were performed with emphasis on the following aspects:
- Equipment operation;

- Coalescence phenomena;

- Fluid dynamics aspects.

\section{RESULTS AND DISCUSSION}

\subsection{Equipment operation}

In Figure 3, it is possible to observe the operation behavior of the mass flow of oil at the outlet of the equipment in comparison to the inlet flow for and inlet flow equal to $85 \mathrm{~L} / \mathrm{h}$ after simulation for both cases (1) and (2).

For a better understanding of Figure 3 , a division of the oil mass flow behaviour in three parts was inserted into the graph. The first (I), called "starting", is characterized by an increasing flow and, after few moments, a decreasing oil flow in the outlet. The starting stage can be understood as the time interval in which the oil present at the initial time $(t=0 \mathrm{~s})$ is swept from the domain, i.e. there is high flow of oil in the outlet due to the small ascent rate and coalescence of the oil present in the back part of the porous domain. In this first stage, the results obtained in the cases analyzed differ significantly in the amount of oil leaving the 


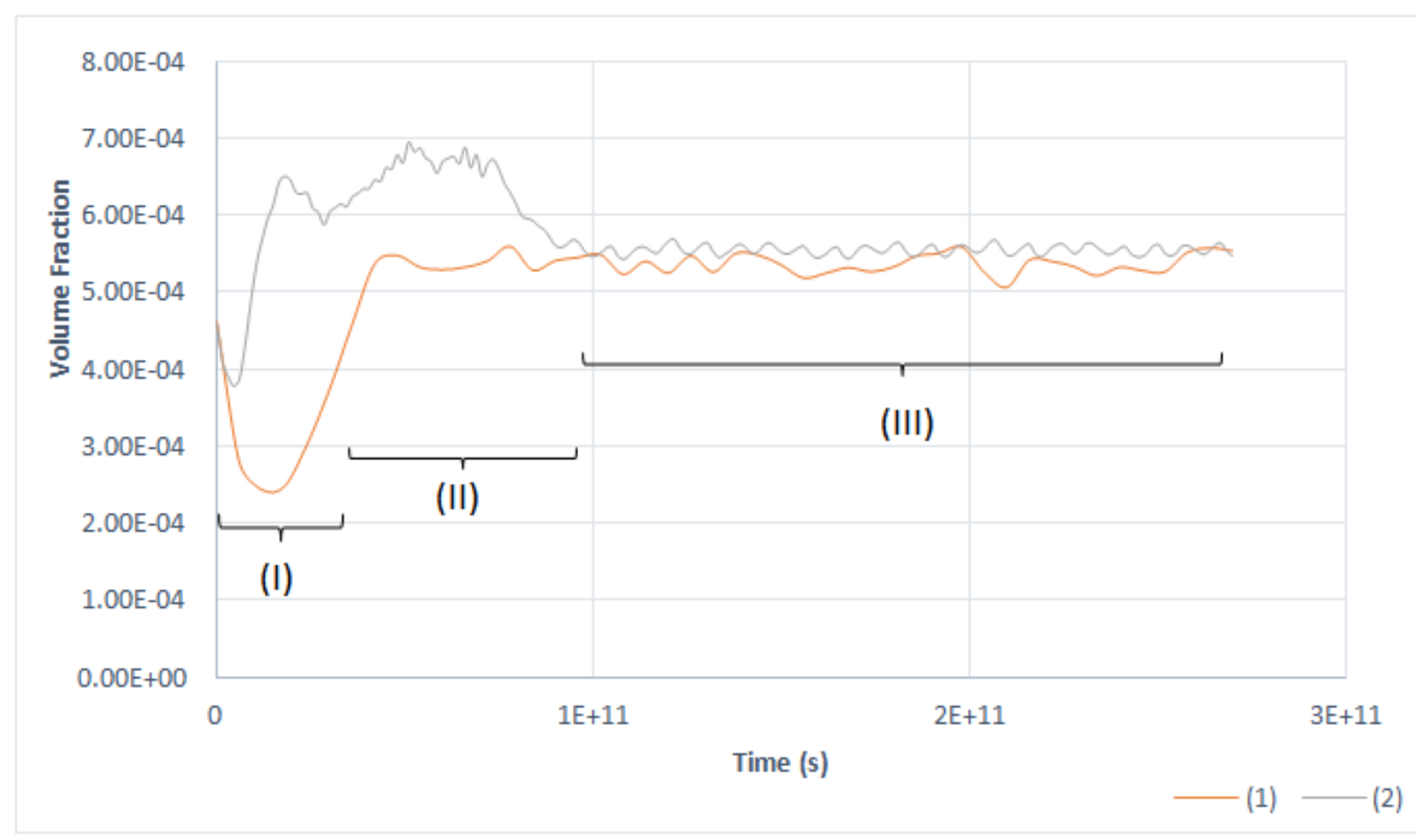

Figure 4. Behaviour of the volumetric fraction of oil in the equipment for an inlet flow rate of $85 \mathrm{~L} / \mathrm{h}$.

equipment. Case (2) presents a higher rate than case (1). One can also observe the occurrence of oil flow oscillation on this stage for the second case.

Then, there is a second increase in the amount of oil, which marks the beginning of the second phase (II), called "transition." At this stage there is the arrival of the oil initially present in the equipment, which begins to enter the equipment. At this stage, there is still oil to be swept from the initial condition, and oil accumulation begins at the final stretch of the domain. The transition stage is characterized by the instability of the output oil rate for both results obtained, which is more notable using case (2) modeling.

Finally, the beginning of a third stage (III) is observed. At this stage, one can see that the cases analyzed presented quite different behaviours. The results obtained with case (1) modeling are characterized by intense instability, with a great variation of the oil flow over time. The results obtained with case (2) show small flow oscillations, if compared with those observed previously. These small oscillations continued throughout stage (III), called "operation" phase for case (2), thus, indicating that the equipment may have reached the state of operation, or an apparent steady state.
Figure 4 displays the stages described previously. It is possible to observe the variation of the volumetric fraction of oil in the equipment over time. A decrease in the amount of oil in the domain at the initial moment (starting) is observed, followed by an increase in the amount of oil (transition). Finally, a relative stabilization of the amount of oil in the domain occurs, with low variations in the flow, possibly caused by minor disturbances in the system (steady state). Motta (2014) observed in his experiments that the efficiency value and, consequently, the amount of oil present in the equipment oscillates until the steady state is reached. This information agrees with the results shown in Figure 4.

Figure 5 displays a similar behavior to the one observed in Figure 3, which had a lower flow rate. However, it is possible to notice that the increase of flow in the system causes the reduction of the duration in the initial stages, starting and transition. Consequently, it reaches a seemingly stationary state earlier for case (2). This response was also observed when analyzing the behaviour of the volumetric fraction of oil with time in the system (Figure 6). 


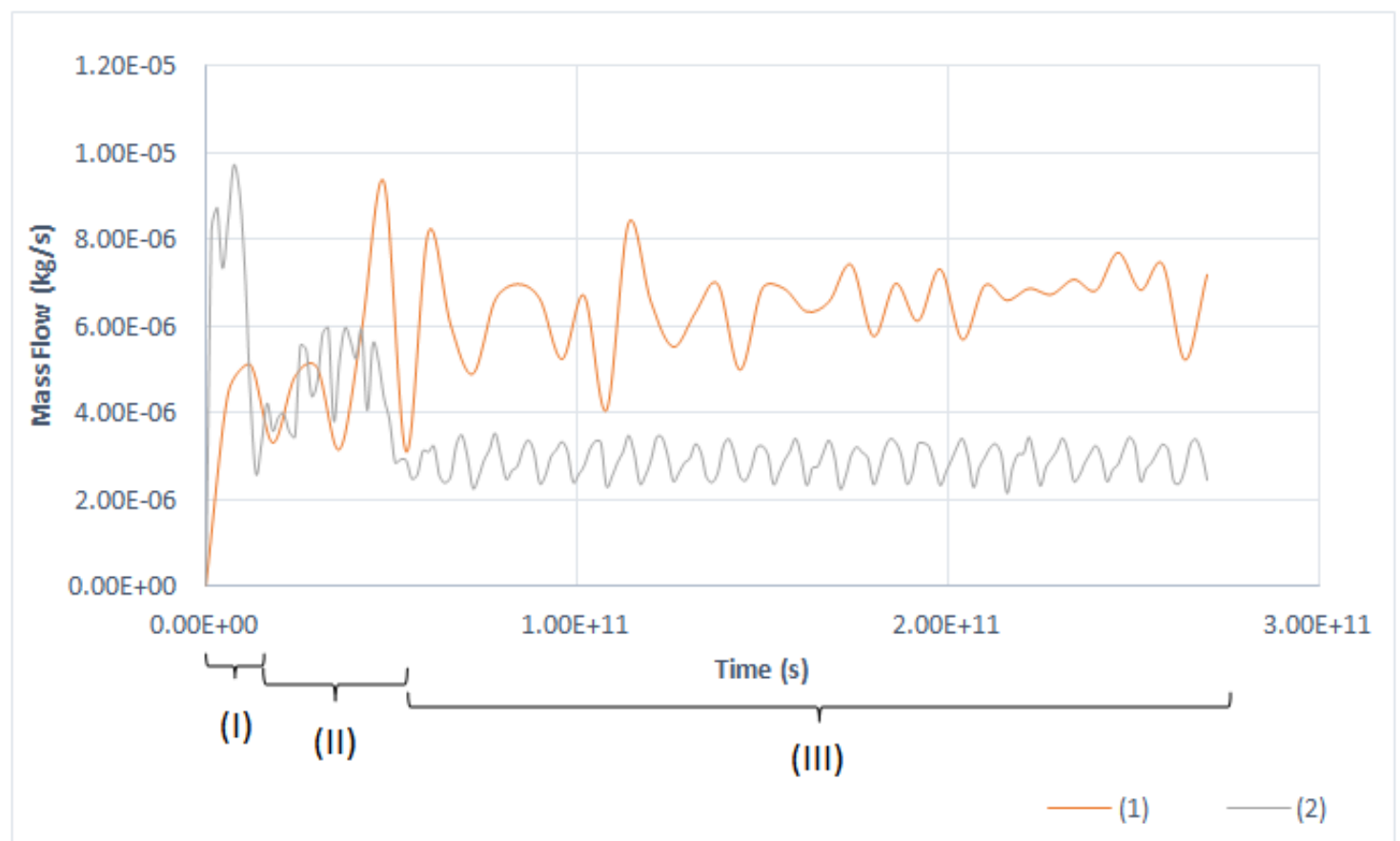

Figure 5. Mass flow of oil at the outlet for an inlet flow of $110 \mathrm{~L} / \mathrm{h}$.

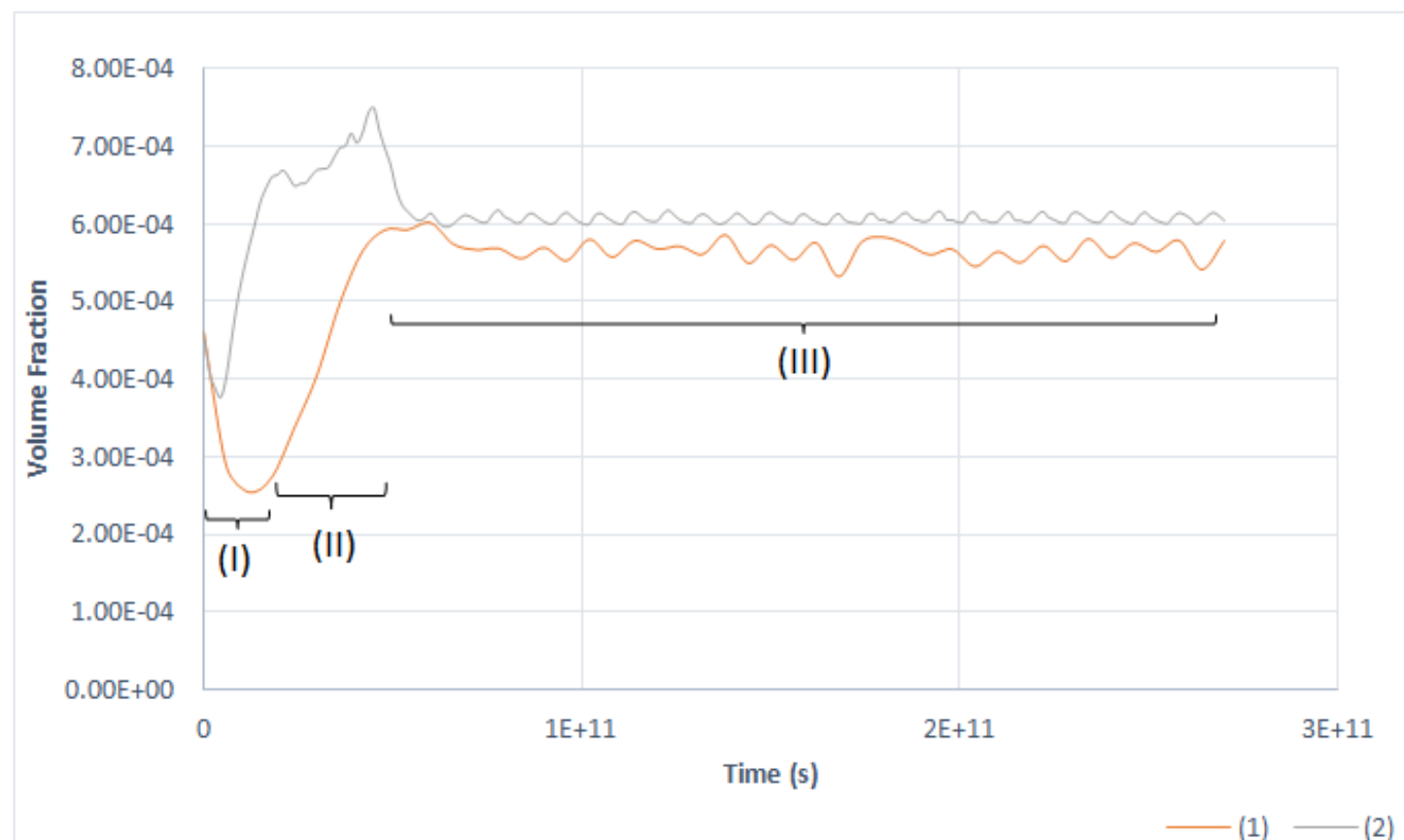

Figure 6. Behaviour of the volume fraction of oil in the equipment for an inlet flow of $110 \mathrm{~L} / \mathrm{h}$.

Based on the results obtained for case (2), Figure 7 proposes a graph for coalescing beds that operate under the conditions analyzed.

In Figure 7, it is possible to observe the stages previously described in Figure 6: starting (I), transition (II), and operation (III). The stages are consistent with the initial and boundary conditions applied, and with durations dependent on the input flow used. 


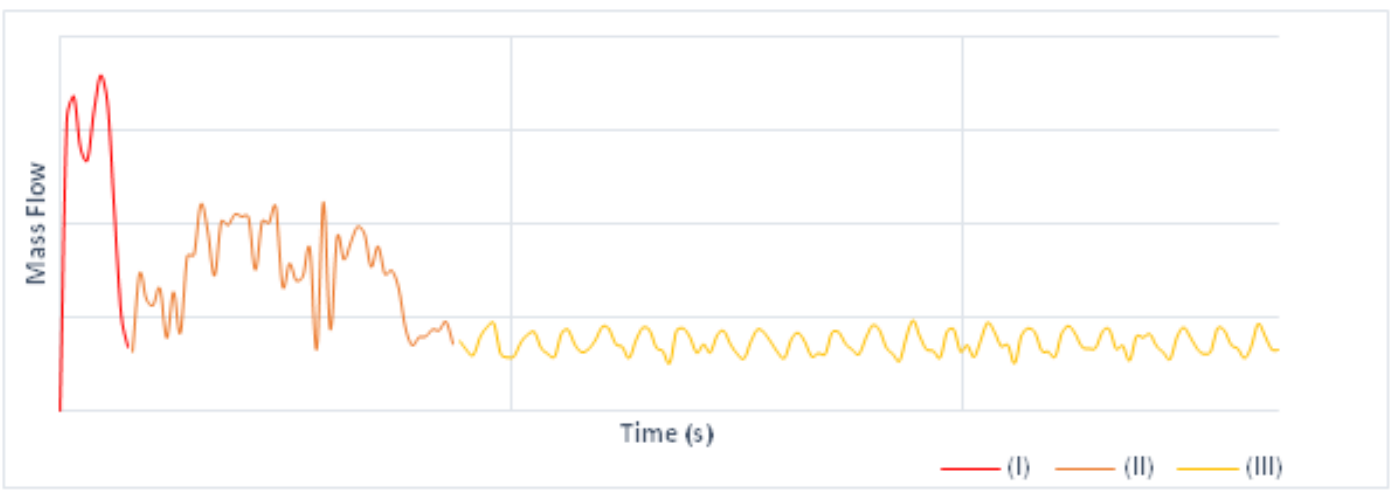

Figure 7. Behaviour of equipment with a coalescer bed in operation.
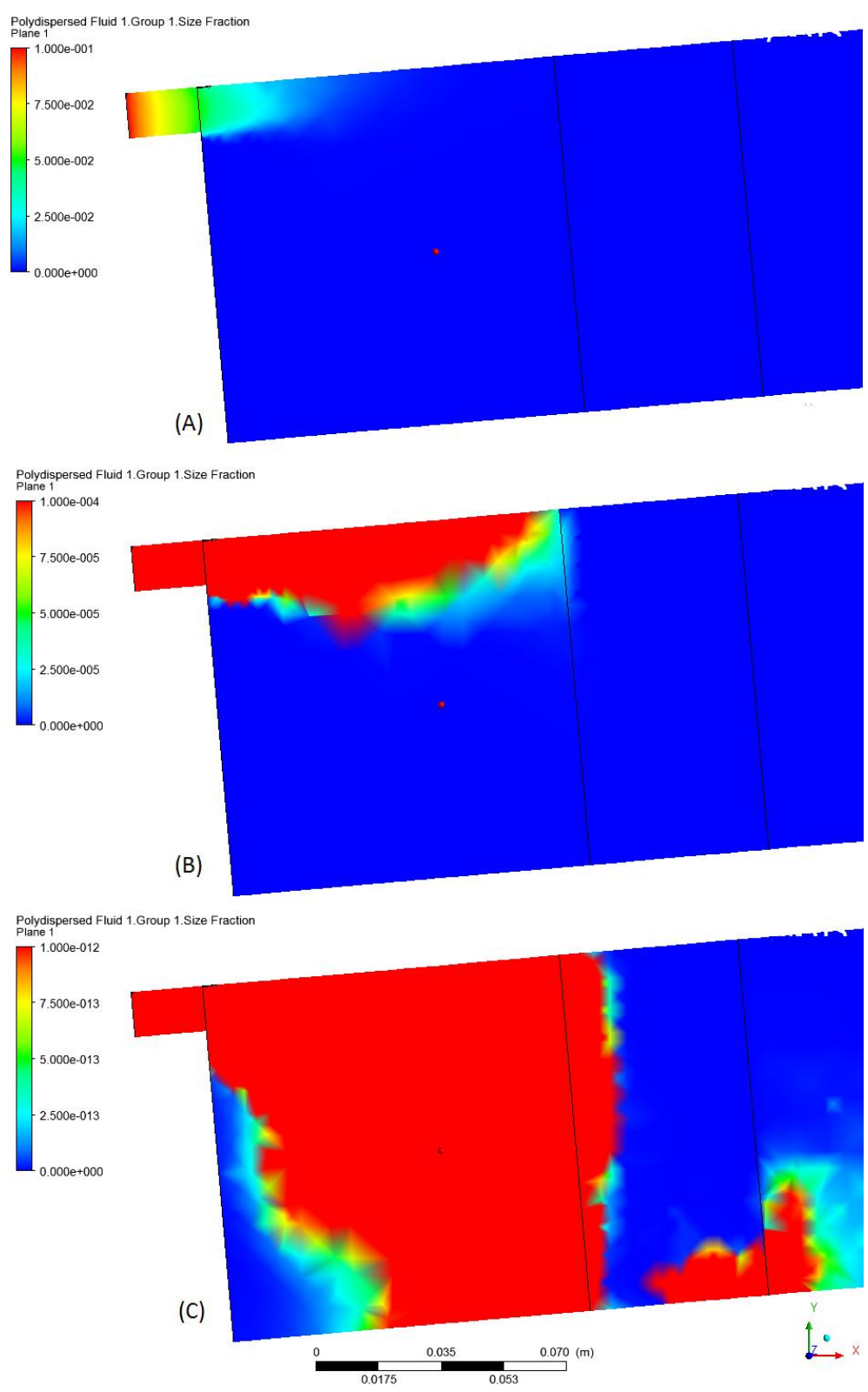

Figure 8. Spatial distribution of particles with a diameter of $50 \mu \mathrm{m}$ with maximum volumetric fraction equal to $10^{-1}$ located near the entrance region. 


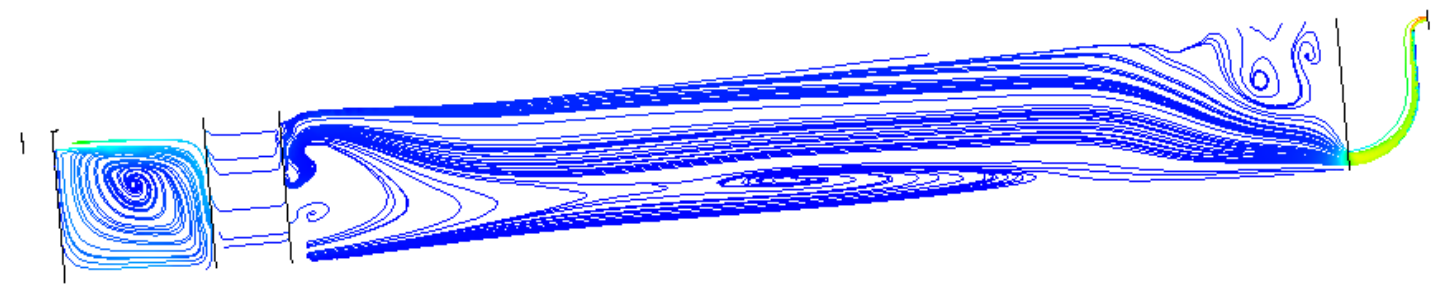

(A)

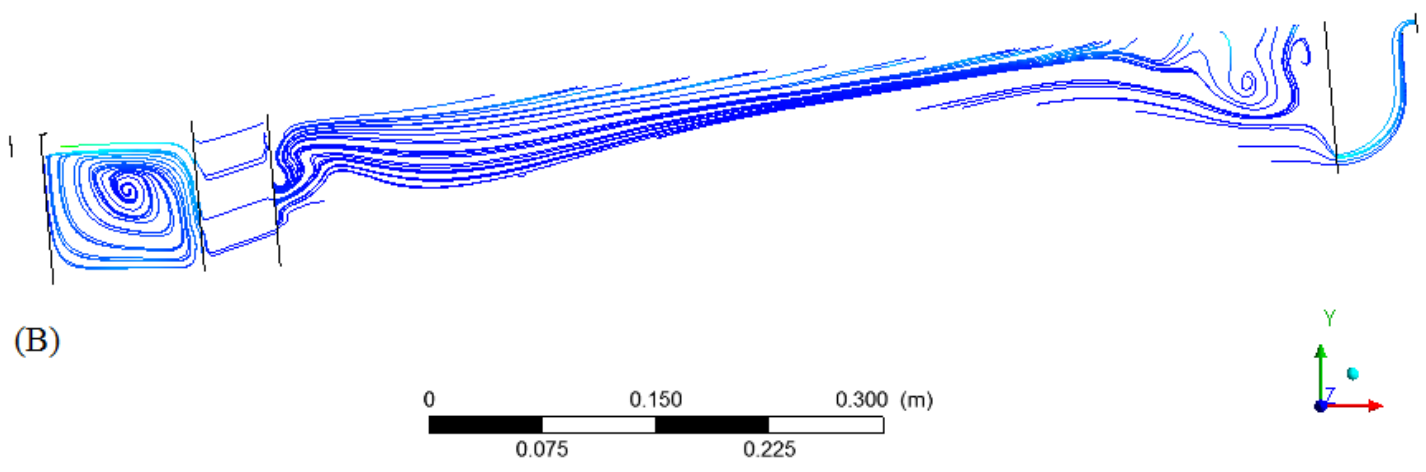

Figure 9. Stream lines for water (A) and oil (B).

\subsection{Coalescence phenomena}

To evaluate the occurrence of coalescence in the model analyzed, vertical planes were created in the domain to observe the spatial distribution of the dispersed phase. In Figure 8, it is possible to visualize this spatial distribution of the $50 \mu \mathrm{m}$ group for different scales. The region studied was between the inlet region and the beginning of the porous bed.

Figure 8 shows planes with maximum volumetric fraction equal to $10^{-1}, 10^{-4}$, and $10^{-12}$, respectively, in $A, B$, and $C$. It is possible to observe that there is a decrease in the volumetric fraction of the particles of diameter equal to $50 \mu \mathrm{m}$, indicating that these particles coalesce, form other particles with large diameters. This result proves that the adopted modelling can reproduce particles interaction and coalescence phenomena (Sokolovic \& Sokolovic, 2004).

\subsection{Fluid dynamics aspects}

To assist in the analysis of the fluid dynamic behaviour of the equipment, stream lines were created in the domain for the water and oil phases, respectively. See Figure 9.

Due to density differences between oil and water, there is a tendency of rising for the dispersed phase (oil) caused by the buoyancy, which is intensified with the increase of particle diameter, i.e., after coalescence phenomenon. Such behaviour can be observed by comparing the stream lines of both phases. Figure 9-b shows that the oil phase stream lines tend migrate to the upper part of the domain, unlike the water phase stream lines (Figure 9-a), which are distributed over all the equipment.

In addition, by observing the stream lines, one can notice that the modelling shows the existence of turbulence for both fluid phases along the domain. This phenomenon is somewhat undesirable in view of the purpose of the equipment (Sareen et. al., 1966; Li \& Gu, 2004), since the presence of turbulence is prejudicial to coalescence for causing the separation of the particles and, consequently, increasing the operation time for the complete process to occur (Prince \& Blanch, 1990).

\section{CONCLUSIONS}

Based on the results obtained using the modeling proposed and on Prince and Blanch Model, it was possible to observe a strong influence of time discretization in equipment behavior. Case (2), which had a greater number of 
timesteps, showed an agreement with the researched literature pertaining the operational proceedings of the equipment. This can be explained by the greater proximity of the 15second timestep of the time scale in which the coalescence phenomena occur in comparison with those of $60 \mathrm{~s}$.

One could also observe that minor oil particles tended to join each other through collision between them, and by contact with a porous material saturated with oil. This phenomenon also was in agreement with the literature and showed high efficiency in using the Prince and Blanch Model to describe coalescence.

The modeling used in case (2) can also be validated with further experiments, as well as enhanced with the insertion of parameters that will provide a better reproducibility of the real behaviour, such as solid-fluid interaction and calibration of the coalescence model.

It is crucial to emphasize the importance of reducing turbulence in the equipment to promote coalescence, as observed in the fluid dynamic analyses. This reduction can be done in two ways. The first one is based in the modification of the properties of the porous bed: the increase of the permeability can avoid zones of pressure drop that favor the formation of vortices. The other way is using different equipment designs, which would reduce vorticity, especially close to inlet and discharge zones.

\section{NOMENCLATURE}

Latin letters:

d Particle diameter $m$

L Length $m$

v speed $\mathrm{m} / \mathrm{s}$

A Area $\mathrm{m}^{2}$

V Volume $\mathrm{m}^{3}$

UVelocity component $\mathrm{m} / \mathrm{s}$

$\vec{U}$ Velocity vector $\mathrm{m} / \mathrm{s}$

g Acceleration of gravity $\mathrm{m} / \mathrm{s}^{2}$

h Film thickness $m$

t Time $s$

$r$ Radius $m$

K Absolute permeability D
Greek letters:

$\alpha$ Inclination Degrees

Y Absolute porosity -

$\mu$ Dynamic viscosity Pa.s

$\rho$ Density $\mathrm{kg} / \mathrm{m}^{3}$

$\sigma$ Interfacial tension $\mathrm{N} / \mathrm{m}$

\section{REFERENCES}

Ahmandun, F.-R.; Pendashteh, A.; Abdullah, L. C.; Biak, D. R. A.; Madaeni, S. S.; Abidin, Z. Z. Review of Technologies for oil and gas produced water treatment. Journal of Hazardous Materials, V. 170, P. 530-551, 2009.

https://doi.org/10.1016/i.jhazmat.2009.05.044

Ahmed, T. Reservoir Engineering Handbook. Gulf Professional Publish, $2^{\text {nd }}$ ed., USA, 2000.

ANSYS CFX 13. User manual. Ansys Europe Ltd., 2011.

Braga, E. R.; Huziwara, W. K.; Martignoni, W. P.; Scheid, C. M.; Medronho, R. A. Improving hydrocyclone geometry for oil/water separation. Brazilian Journal of Petroleum and Gas, v. 9, n. 3, p. 115-123, 2015.

https://doi.org/10.5419/bjpg2015-0012

Cai, X.; Chen, J.; Liu, M.; Zhang, L. CFD simulation of oil-water separation characteristics in a compact flotation unit by population balance modeling. Journal of Dispersion and Technology, v. 38, n. 10, p. 1435-1447, 2016.

https://doi.org/10.1080/01932691.2016.1251323

Chesters, A. K.; Hofman, G. Bubble coalescence in pure liquids. Applied Scientific Research, v. 38, n. 1, 353-361, 1982.

https://doi.org/10.1007/BF00385965

Coelho, D. B. Desempenho de um hidrociclone paras separação de águas oleosas. $52 \mathrm{f}$. Monografia. Departamento de Engenharia Química, Universidade Federal do Rio Grande do Norte, Natal, RN. 2011. (in Portuguese).

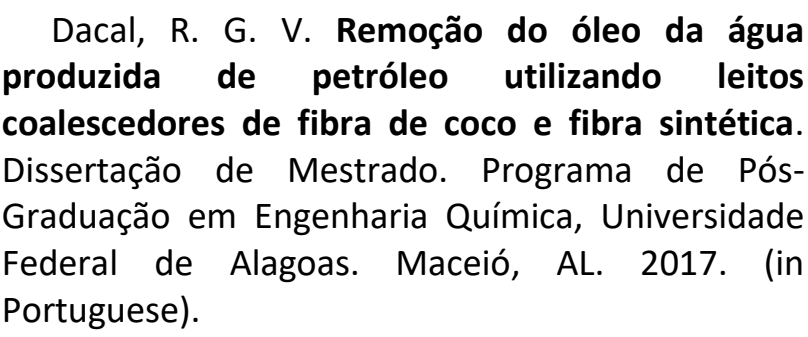


Ferreira, D. N.; Marinho, J. L. G.; Oliveira, L. M. T. M. Study of pressure drop in a horizontal pipe with a $90^{\circ}$ junction for biphasic liquid-gas flow: mesh aspects. Brazilian Journal of Petroleum and Gas, v. 11, n.1. p. 31-42, 2017. https://doi.org/10.5419/bipg2017-0003

Govedarica, D. D.; Sokolovic, R. M. S.; Sokolovic, D. S.; Sokolovic, S. M. A novel approach for the estimation of the efficiency of steady-state fiber bed coalescence. Separation and Purification Technology, v. 104, p. 268-275, 2013. https://doi.org/10.1016/j.seppur.2012.11.034

Huang, Si. Numerical simulation of oil-water hydrocyclone using reynold-stress model for eulerian multiphase flows. The Canadian Journal of Chemical Engineering, v. 83, n. 5, p. 829-834, 2005. https://doi.org/10.1002/cjce.5450830504

lida, P. H.; Scheer, A. P.; Weinschutz, R.; Santos, B. M. Estudo do efeito da água em emulsões de petróleo. IV Congresso Brasileiro de P\&D em Petróleo e Gás. Campinas, SP. 2007. (in Portuguese).

Ishii, M.; Zuber, N. Drag coefficient and relative velocity in bubbly, droplet or particulate flows. AIChE Journal, v. 25, n. 5, p. 843-855, 1979. https://doi.org/10.1002/aic.690250513

Levich, V. G. Physicochemical hydrodynamics. Journal of Chemical Education, 1963, 40(10), $p$ A827.

Li, J.; Gu, Y. Coalescence of oil-water emulsions in fibrous and granular beds. Separation and Purification Technology, v. 42, n. 1, p. 1-3, 2004. https://doi.org/10.1016/j.seppur.2004.05.006

Lopes, A. C. D. Estudo da remoção de óleos emulsionados de efluentes industriais. Dissertação de Mestrado. Faculdade de Engenharia, Universidade do Porto. Porto, POR, 1999. (in Portuguese).

Maiti, S.; Mishra, I. M.; Bhattacharya, S.D.; Joshi, J.K. Removal of oil from oil-water emulsion using a packed bed of commercial resin. Colloids and Surfaces A: Physicochemical and Engineering Aspects, v. 389, n. 1-3, p. 291-298, 2011. https://doi.org/10.1016/i.colsurfa.2011.07.041
Marinho, J. L. G. Escoamento anular isotérmico de óleos pesados e água em bifurcações angulares: modelagem e simulação. Tese de doutorado. Programa de Pós-Graduação em Engenharia de Processos, Universidade Federal de Campina Grande, 2012. (in Portuguese)

Martins, C. S. Projeto de um sistema de tratamento da água produzida de reservatórios de petróleo para sua adequação ao consumo humano. 74f. Monografia. Departamento de Engenharia de Petróleo, Universidade Federal do Rio Grande do Norte. Natal, RN, 2015. (in Portuguese).

Motta, A. R. P. Tratamento de água produzida de petróleo para remoção de óleo através da integração dos processos com coalescedor em leito e microfiltração. 256f. Tese de doutorado. Escola Politécnica, Programa de Pós-Graduação em Engenharia Industrial, Universidade Federal da Bahia. Salvador, BA. 2014. (in Portuguese).

Motta, A. R. P.; Borges, C. P.; Kiperstok, A.; Esquerre, K. P.; Araujo, P. M.; Branco, L. P N. Tratamento de água produzida de petróleo para remoção de óleo por processos de separação por membranas: revisão. Engenharia Sanitária e Ambiental, v. 18, n. 1 , p. $15-26,2013$. (in Portuguese). $\quad$ https://doi.org/10.1590/S1413$\underline{41522013000100003}$

Motta, A. R. P.; Borges, C. P.; Kiperstok, A.; Esquerre, K. P. Utilização de coalescedor com leito de resinas de trocas catiônicas para pré-tratamento de óleo emulsionado em efluentes líquidos. Engenharia Sanitária e Ambiental, v. 20, n. 2, p. 235-242, 2015.2 (in Portuguese). https://doi.org/10.1590/S1413$\underline{41522015020000116813}$

Munson, B. R.; Young, D. F.; Okiishi, T. H. Fundamentals of Fluid Mechanics. New York: John Wiley \& Sons, Inc., 4th Edition, 2002.

Prince, M. J.; Blanch, H. W. Bubble coalescence and break-up in air-sparged buble columns. AIChe Journal, v. 36, n. 10, p. 1458-1499, 1990. https://doi.org/10.1002/aic.690361004

Sareen, S. S.; Rose, P. M.; Gudesen, R. C.; Kintner, R. C. Coalescence in Fibrous Bed. AIChe Journal, v. 12, n. 6, p. 1045-1050, 1966. https://doi.org/10.1002/aic.690120603 
Silva, C. R. R. Água produzida na extração de petróleo. 27f. Monografia. Escola Politécnica, Universidade Federal da Bahia. Salvador, BA. 2000. (in Portuguese).

Sokolovic, R. M. S.; Sokolovic, S. M. Effect of the nature of different polymeric fibers on steady-state bed coalescence of an oil-in-water emulsion. Industrial and Engineering Chemistry Research, v. 43, n. 20, p. 6490-6495, 2004. https://doi.org/10.1021/ie049742h
Speth, H.; Pfennig, A.; Chatterjee, M.; Franken, $\mathrm{H}$. Coalescence of secondary dispersions in fiber beds. Separation and Purification Technology, v. 29, n. 2, p. 113-119, 2002.

https://doi.org/10.1016/S1383-5866(02)00067-9

Spielman, L. A.; Su, Y.-P. Coalescence of oilwater suspensions by flow through porous media. Industrial and Engineering Chemistry Fundamentals. v. 16, n. 2, 272-282, 1977. https://doi.org/10.1021/i160062a018 